\title{
A Survey of Business Ethics in Universities
}

\author{
Milad Yousefi, Mehdi Karimimalayer, Salomeh Izadyar, and Ali Akbar Falahnejad Tafti
}

\begin{abstract}
University students are considered the next generation of high level managers that can affect the goals and aims of organizations and society. In recent decades one of the most important issues in organizations and society is ethics. Academic ethics and business ethic have a direct relation with each other. This research tries to investigate unethical issues in universities. In order to achieve this goal a survey conducted among 440 students of management and accounting in local universities in Tehran, the capital of Iran. The calculated data was analyzed by SPSS software and popularity of each unethical behavior and attitude of students about them were analyzed.
\end{abstract}

Index Terms-Business ethics, academic ethics, unethical behaviors, students of management.

\section{INTRODUCTION}

Ethics is about "the moral principles that govern a person's behavior or the way in which the activity is conducted" [1]. Ethics is concerned with moral obligation, responsibility, and social justice [2]. Business ethics has been and it will continue to be a hot topic for some years in the future. Business ethics is a range of criteria whereby human actions are judged to include such things as societal expectations; fair competition; the aesthetics of advertising and the use of public relations; the meaning of social responsibilities; reconciling corporate behavior at home with behavior abroad; the extent of consumer sovereignty; the relevance of corporate size; the handling of communications, and the like [1]. The ethics boom first started in the 1960's [2] and in the 1980's it was mentioned as a factor of political and social development [3]. Henceforth, Business ethics has been a major concern of researchers in business [2] [4]. As a matter of fact unethical behaviors are not built all of a sudden but grow steadily over the years. From this point of view as management students are considered to be the next generation of managers, the education system has its role in the unethical actions of the managers [5] [6]. Hence in the recent years more ethics courses has been added to the courses at universities and schools [7] and ethics courses have become arbitrary in lots of management schools. Statistics shows that just in the year 1993 more than 500 ethics seminars was held in united stated and more than $90 \%$ of the universities had ethics course in their programs [8]. Since there is not a significant difference between students and graduates in the case of ethical orientation, studying the ethical orientation

Manuscript received May 9, 2012; revised June 11, 2012.

Milad Yousefi and Ali Akbar Falahnejad Tafti are with university of Tehran, Iran (yousefi.milad@gmail.com).

Mehdi Karimimalayer and Salomeh Izadyar are with University Putra Malaysia. of management students helps better understanding of next generation of managers' ethical orientation [9].

The desire to get a high mark in the exam as well as low risk of getting caught and not studying well are mentioned to be the main reasons of cheating [10]. The high stress level of students and improper regulations of university are among the other reasons of cheating [9]-[11]. Some researches indicate that cheating as unethical behaviors in the reverse.

In different works the effects of different factors on occurrence of unethical behaviors have been investigated. Generally these factors are categorized in two groups, individual characteristics and the environmental effects [12]. The individual characteristics that have been concerned in previous works are age, sex, education and locus of control where the environmental factors are culture, religion orientation and ethical orientation of other people around the person.

In some other works the teachers and staff have been the subject of researches on academic ethics. Some subjects such as "accepting gifts or money to give higher marks"," sexual harassment" and plagiarism have been investigated [13]. Another research indicated that the majority of unethical behaviors among the marketing professors are bribing, sexual harassment, plagiarism and participating in forging of academic certifications [5]. A recent work that was conducted on 2008 indicates that $83 \%$ of students believe that the most common unethical behavior among teachers is giving lower marks to students that have personal problems with them. These problems include simple ones such as arguments about a subject in the class. The second common unethical behavior is disclosure of personal information of students to others. $80 \%$ of students were for this [14]. The opinions of management students on the intensity and importance of ethics matters in organizations have been investigated also [10]-[16]. Some researches indicate that women are more committed to the business ethics than men [17]-[18].

\section{Methodology}

\section{A. Sample Size}

Number of samples was calculated by this formula:

$$
n=\frac{z_{\alpha / 2}^{2} p(1-P)}{\varepsilon^{2}}
$$

For qualitative features variance is between 0 and 0.25 then we chose highest variance to calculated sample. On the other hand accepted error was 5\% then size of sample was:

$$
n=\frac{1 / 96^{2} 0 / 25}{(0 / 05)^{2}}=348
$$


To reach the aims of this study 854 questionnaire was distributed between management and accounting students in universities located in Iran capital city, Tehran. The number of questionnaire that were completed correctly and therefore could be used in the research was 409 . For this study according to sample size 348 was used in analyzing. The questionnaire has three parts. The first part is about personal information. The demographic information of respondents is shown in the table 1 . Another part of this questionnaire is about the unethical behaviors in the universities that is based on the work of Pratt and McLaughlin(1988) that has fourteen questions. To adapt the questionnaire to the local culture of Iran, the questions were modified using opinions of experts and five more questions were added to make it more thorough. Every question consider an unethical behavior of students at universities. The questions can be seen in the appendix. In the questionnaire the respondents were asked to rank the mentioned unethical behavior in any question between 1 to 5 which 1 indicates a completely unethical behavior and 5 is ethical action. This part is was designed to investigate the ethics orientation of students.

TABLE I: DEMOGRAPHIC DATA

\begin{tabular}{|c|c|c|c|c|c|}
\hline Percentage & Frequency & Age & Percentage & Frequency & \\
\hline$\% 21$ & 74 & Under 20 & $\% 2$ & 7 & Freshmen \\
\hline$\% 65$ & 226 & $21-25$ & $\% 10$ & 34 & $\begin{array}{c}\text { Second- } \\
\text { year }\end{array}$ \\
\hline$\% 14$ & 48 & Upper 26 & $\% 77$ & 269 & Last year \\
\hline$\% 100$ & 348 & Total & $\% 11$ & 38 & $\begin{array}{c}\text { MS \& } \\
\text { PhD }\end{array}$ \\
\hline Percentage & Frequency & Accommodation & $\% 100$ & 348 & Total \\
\hline$\% 47$ & 162 & With family & Percentage & Frequency & Sex \\
\hline$\% 13$ & 46 & Nearby cities & $\% 53$ & 184 & Male \\
\hline$\% 40$ & 140 & dormitory & $\% 47$ & 164 & Female \\
\hline$\% 100$ & 348 & Total & $\% 100$ & 348 & Total \\
\hline
\end{tabular}

The questions were designed in a way that students would be able to answer them without bias. For this reason instead of asking students to answer the questions about themselves they were asked to tell their opinions in general about the question. It was shown in the work of Stevens and also Tyson that students think they are more committed to the ethics than others.

TABLE II: RELIABILITY STATISTICS Reliability Statistics

\begin{tabular}{|c|c|c|}
\hline Cronbach's Alpha & $\begin{array}{l}\text { Cronbach's Alpha } \\
\text { Based on } \\
\text { Standardized Items }\end{array}$ & $\mathrm{N}$ of Items \\
\hline 0.874 & 0.886 & 19 \\
\hline
\end{tabular}

Reliability for each question:

The statistics shows that all questions are reliable enough since their reliability factor is above 0.8 .

According to table Cranach's $\alpha$ for collection of questions is (91.6) excellent and for every questions separately is upper than $90 \%$ which means very good.

\section{B. Validity}

Validity is a term that shows to a test that created for achieving specific goal. According to reach acceptable reliability experts, lecturers and students were asked to help preparing the questionnaire.

\section{One Sample Test}

In this part according to guide table, the questions that give score 4 or 5 are in a good condition. In the other words, when an unethical behavior happens rarely in a community we can say this community is in a good condition

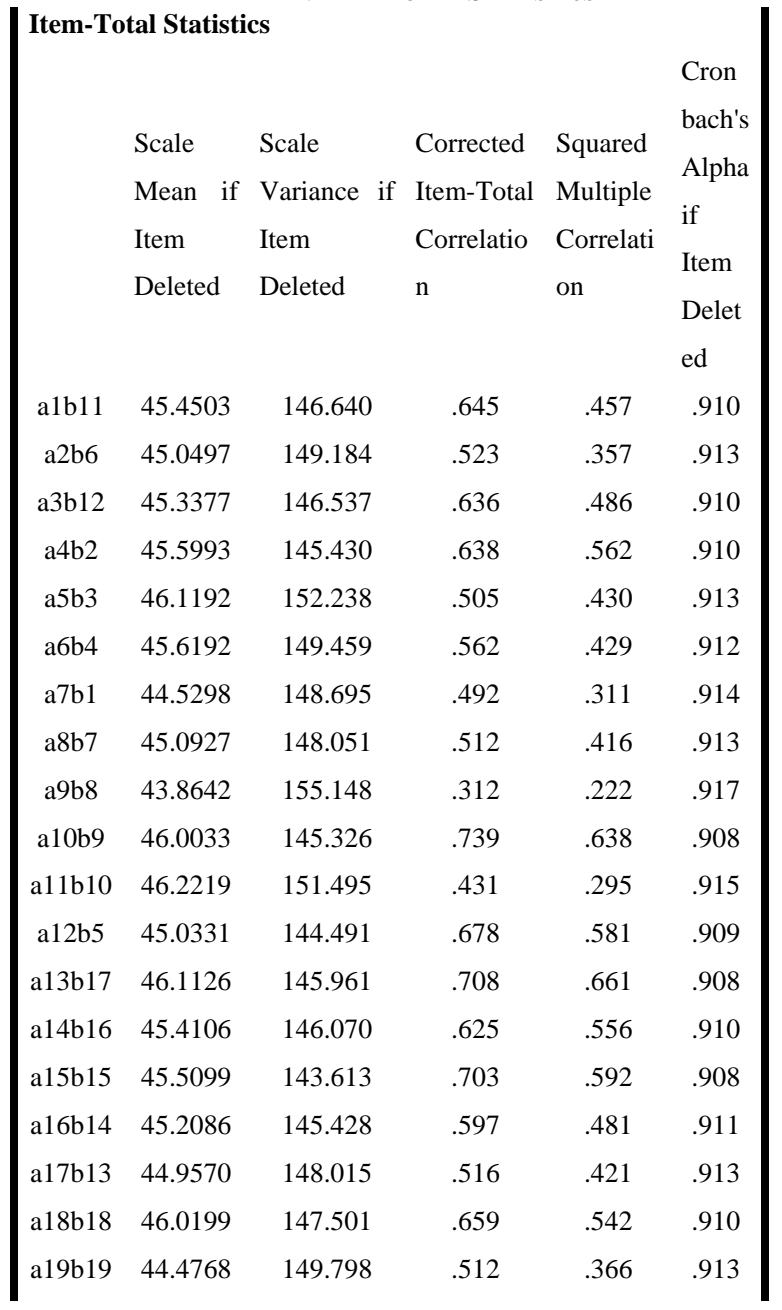

TABLE IV. GUIDE TABLE OF QUESTIONNAIRE

\begin{tabular}{|l|l|l|l|l|}
\hline $\mathbf{5}$ & $\mathbf{4}$ & $\mathbf{3}$ & $\mathbf{2}$ & $\mathbf{1}$ \\
\hline Never & Rarely & Sometimes & Often & Always \\
\hline
\end{tabular}

For achieving this goal and finding popularity of unethical behaviors following hypothesis test was used. In this hypothesis $\mu$ was 3 which means if interviewee selects a number less than 3 it could show popularity of unethical business behaviors and If selects a number more than 3 it could show society is in good condition.

$$
\begin{aligned}
& \mathrm{H}_{0}: x \neq \mu \\
& \mathrm{H}_{1}: x=\mu
\end{aligned}
$$

Following table includes data about the test of $\mu=3$. Responses show in 2 different colors. Then the analyses about them were found. 


\section{RESULTS AND DISCUSSION}

Questions b4, b14, b16

These questions they are not in good condition or very bad condition. We cannot say that this question never happened at universities. Sometimes they happened.

Questions b9, b10, b11, b15, b17, b18

These unethical behaviors rarely happened by students. We can say students are in a good condition to avoid from these unethical behaviors. As it mentioned in this study score of 4 or 5 is accepted then it shows these unethical behaviors rarely or never happened.

\section{TABLE V: ONE-SAMPLE TEST}

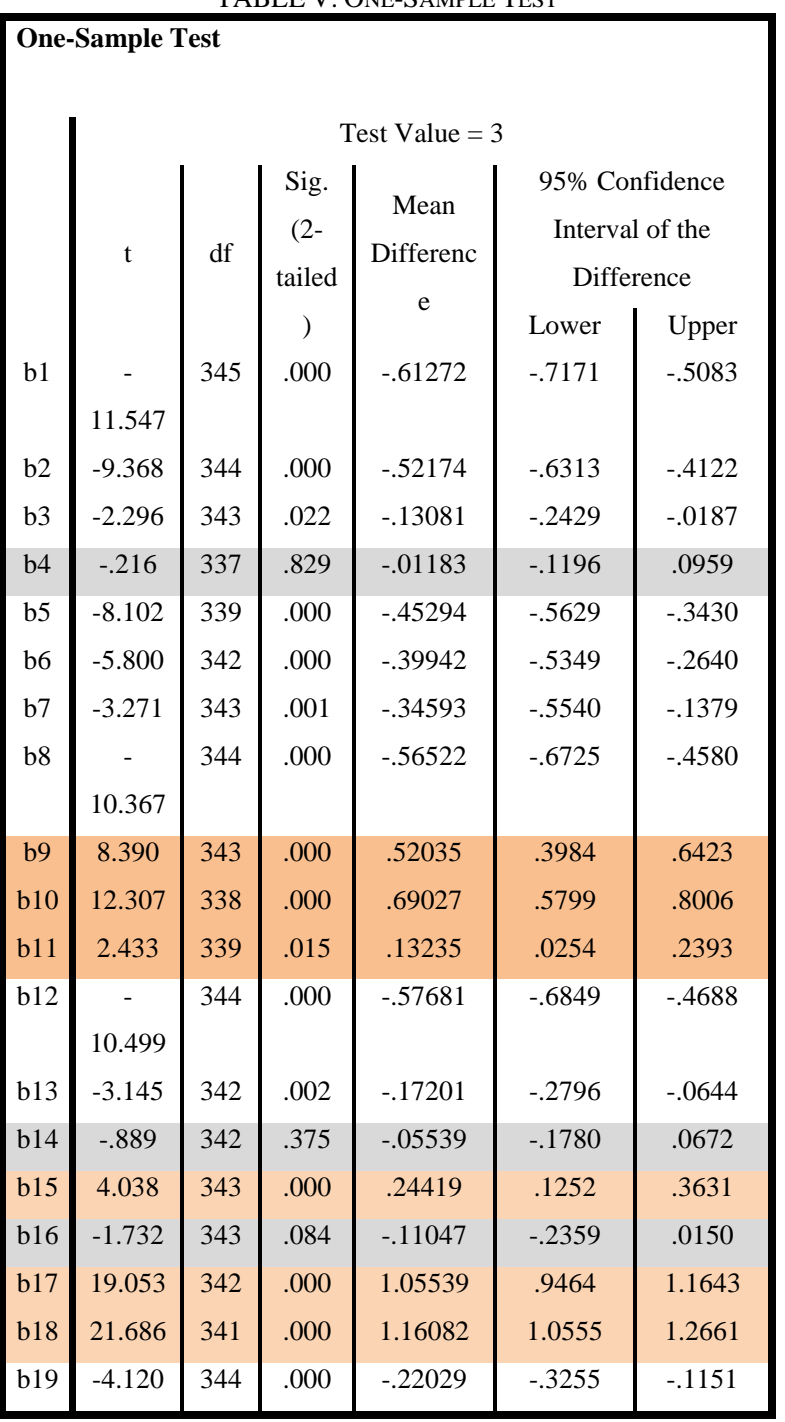

Other questions: b1, b2, b3, b5, b6, b7, b8, b12, b13, b19

These unethical behaviors were in a bad condition which means they happened always at universities. In the following you can find most frequently committed unethical behaviors among students.

Using other students notes instead of their own notes in the class

Cheating in the exams

In group assignments try not to work as hard as others

Help their friends by cheating

After exams try to find lecturer and talk with him/her to give them higher marks.

Try to find questions for last semester and study them for exam.

Copying their assignments instead of do them by themselves.

Writing in exam papers about their problems and try to deceive lecturer give higher mark .

Doing individual assignments in group.

Comparison of questions from two point of view: occurrence and attitude

As it was mentioned in the first part, questions b1, b8, b13, b19 were not unethical in students attitudes and part two of questionnaire shows these unethical behaviors were not popular.

According to descriptive statistics, students in last year of studying do unethical behaviors, like cheating in exams, more than others, especially students whose study are longer than normal.

\section{REFERENCES}

[1] G. Gbadamosi, "Academic ethics: what has morality, culture and administration got to do with its measurement?," Management Decision, vol. 42, no. 9, pp. 1145-1161, 2004.

[2] R. J. Aldag and Stearns, T. M. Management, South Western Publishing Co: Cincinnati, 1991.

[3] M. Davis, "Ethics and risk assessment," Perspectives on the professions, vol. 9, 1990.

[4] B. Macfarlane, Business ethics: too little, too late, Education and Training, vol. 37, no. 5, pp. 36-40, 1995

[5] E. Karassavidou and N. Glaveli, "Towards the ethical or the unethical side: An explorative research of Greek business students' attitudes,' International Journal of Educational Management, vol. 20 no. 5, pp. $348-364,2006$.

[6] A. B. Pizzolatto and S. Bevill, "Business ethics: a classroom priority?," Journal of Business Ethics, vol. 15, pp. 153-158, 1996.

[7] S. Peppas, "Attitudes toward Codes of Ethics: the Effects of Misconduct," Management Research News, vol. 26, no. 6, pp. 77-89, 2003.

[8] N. Smith et al., "National culture and the values of organizational employees: a dimensional analysis across 43 nations," Journal of Cross-Cultural Psychology, vol. 27, pp. 231-264, 1996.

[9] D. L. McCabe and L. K. Treviño, "Academic dishonesty: Honor codes and other contextual influences," Journal of Higher Education, vol. 64, pp. 522-538, 1993.

[10] B. S. Brown, "The academic ethics of graduate business students: A survey," Journal of Education for Business, vol. 70, no. 3, pp. 151156, 1995.

[11] D. L. McCabe, L. K. Trevino, and K. D. Butterfield: "Dishonesty in Academic Environments," Journal of Higher Education, vol. 72, no. 1, 29-45, 2001. 